\title{
Clinical and therapeutical aspects of dental impaction
}

\author{
Aspecte clinico-terapeutice în incluzia dentară
}

\author{
Mioara Decusară, Cerasella Dorina Şincar, Gabriel Valeriu Popa \\ Departamentul de Medicină Dentară, Facultatea de Medicină şi Farmacie, \\ Universitatea „Dunărea de Jos“, Galaţi, România
}

\begin{abstract}
Introduction. Dental impaction represents the group of isolated dental anomalies characterized by retention of a tooth with a fully formed root in the jaw bone, after the eruption period has passed. This anomaly may affect deciduous teeth, permanent or supernumerary teeth causing aesthetic and / or functional disorders.

Case report. The case presents a clinical situation of a girl who presented two maxillary teeth impacted (a central incisor and a cuspid) who underwent surgical exposure and orthodontic treatment for their arch alignments.

Conclusions. Impacted teeth may produce dental malpositions or root resorption of the adjacent teeth, cysts or chronic local infections, which carry out a surgical orthodontic treatment, complex and for a long term, depending on the clinical situation existing.
\end{abstract}

Keywords: dental impaction, orthodontic treatment

\section{REZUMAT}

Introducere. Incluzia dentară se încadrează în grupa anomaliilor dentare izolate de erupţie, fiind caracterizată prin retenţia unui dinte cu rădăcina complet formată în interiorul osului alveolar, după ce termenul de erupţie a trecut. Această anomalie poate afecta dinţii de lapte, dinţii permanenţi sau supranumerari, determinând tulburări estetice şi/sau funcţionale.

Prezentare de caz. Cazul prezintă situaţia clinică a unei paciente cu doi dinţi maxilari incluşi (un incisiv central şi un canin), la care s-a efectuat expunerea chirurgicală a acestora şi tratament ortodontic pentru alinierea pe arcadă.

Concluzii. Dinţii incluşi pot determina malpoziții dentare sau resorbţii radiculare ale dinţilor adiacenţi, chisturi sau infecţii cronice locale, ceea ce impune efectuarea unui tratament ortodontico-chirurgical, complex şi de lungă durată, în funcţie de situaţia clinică existentă.

Cuvinte cheie: incluzie dentară, tratament ortodontic

\section{INTRODUCERE}

Prezența dinților în cavitatea bucală este rezultatul unui proces fiziologic complex reprezentat de erupția dentară. Retenția unor dinți în osul alveolar este influențată de factori locali-regionali sau generali, care pot modifica dinamica erupţiei dentare (1).

Factorii locali incriminați sunt:

- poziţia intraosoasă profundă a mugurelui dentar;

- obstacole în calea de erupție a dintelui (chisturi, tumori, dinți supranumerari, odontoame, fibromucoasă densă etc.);
- malformații ale germenilor dentari (coronare, radiculare sau corono-radiculare);

- micşorarea spaţiului necesar erupției (din cauza macrodonției, dezvoltării insuficiente a maxilarelor în plan transversal, a meziopoziţiei generalizate, determinată de pierderea precoce a dinţilor de lapte din zona de sprijin prin rizaliză patologică sau extracții);

- pierderea provizorie sau definitivă a potențialului de erupție a dintelui.

Ca factori generali amintim:

- tulburări endocrine, metabolice, neuro-psihice, avitaminoze, malnutriția; 
- sindroame genetice (Down, Turner);

- dizostoza cleidocraniană;

- despicături labio-maxilo-palatine;

- ereditatea $(2,3)$.

La examenul clinic intraoral se constată persistența pe arcadă a dintelui de lapte sau absența dintelui definitiv, cu sau fără prezența unor malpoziții dentare, procese inflamatorii ale mucoasei orale, examenul radiologic fiind indispensabil pentru stabilirea diagnosticului cert de incluzie şi a poziţiei dintelui inclus $(4,5)$.

Incluzia dentară apare de regulă la dinții definitivi, în ordinea frecvenței distribuția fiind următoarea: molarii de minte mandibulari, molarii de minte maxilari, caninii maxilari, premolarii mandibulari şi maxilari, incisivii centrali maxilari, caninii mandibulari, incisivii mandibulari, primii molari superiori şi inferiori şi molarii secunzi superiori şi inferiori $(6,7,8)$.

\section{PREZENTARE DE CAZ}

Pacienta G.F., de 11 ani, s-a prezentat la cabinetul de ortodonție, la recomandarea medicului stomatolog, din cauza persistenței lui 61, fără mobilitate fiziologică. Ca antecedente personale, mama a
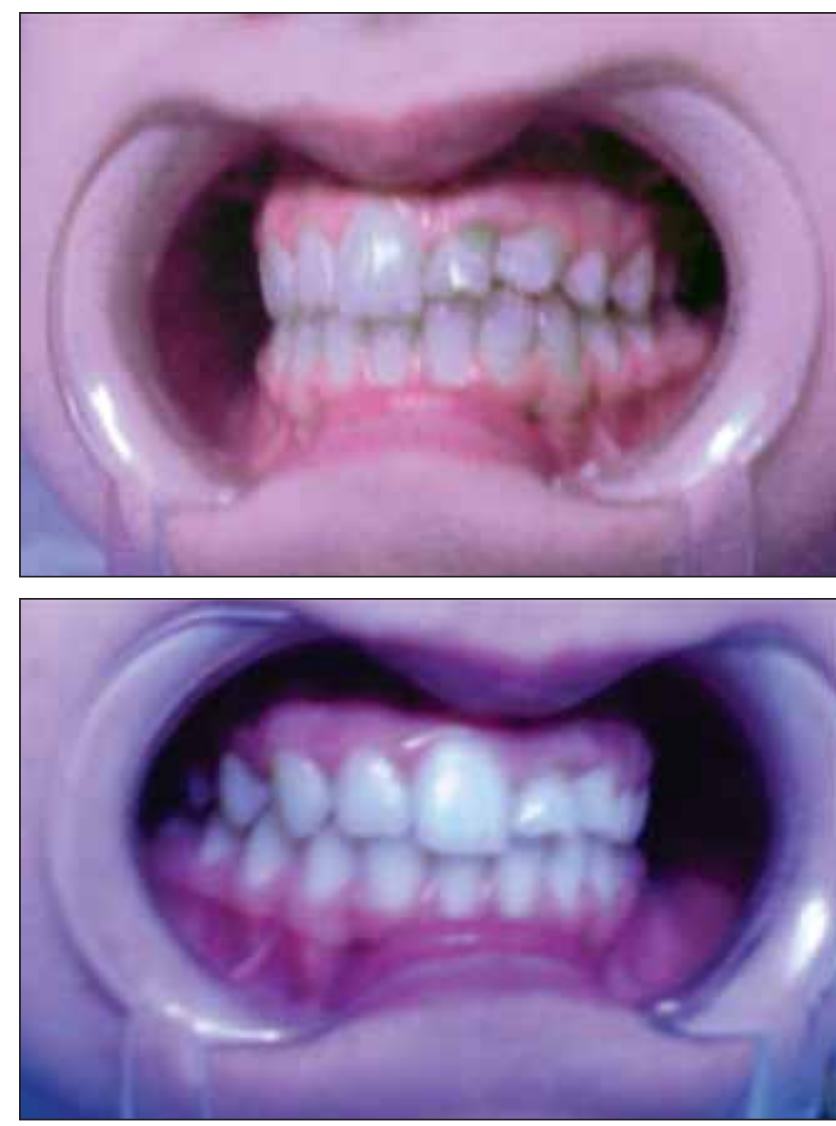

afirmat că, la vârsta de 3 ani, pacienta, prin cădere, a suferit un traumatism dentar la incisivii maxilari.

La examenul clinic intraoral s-a constatat (Fig. 1):

- dentiție mixtă, cu prezența lui 61 şi 63 fără mobilitate fiziologică;

- fractura marginii incizale la nivelul lui 61, fără sensibilitate dentară;

- 36 cu leziune carioasă profundă, netratată, complicată cu fenomene inflamatorii pulpare;

- înclinarea mezială a coroanei lui 22 determinată, cel mai probabil, de dinții adiacenți definitivi incluşi;

- ocluzie statică neutrală la nivel molar şi canin, bilateral, şi la nivel frontal;

- corespondența liniilor mediane şi interincisive intermaxilare;

- supraacoperire frontală în limite normale.

Pe ortopantomogramă s-a remarcat (Fig. 2):

- distrucția coronară importantă la 36 , cu absența radiotransparenței periapicale, determinată de o eventuală inflamație periapicală;

- resorbție radiculară fiziologică redusă la nivelul lui 62 şi 63 ;

- 21 şi 23 incluşi, cu 21 disto-înclinat $30^{\circ}$ față de mediana maxilară şi 23 mezio-înclinat $45^{\circ}$ față de paralela la mediana maxilară, coroa-

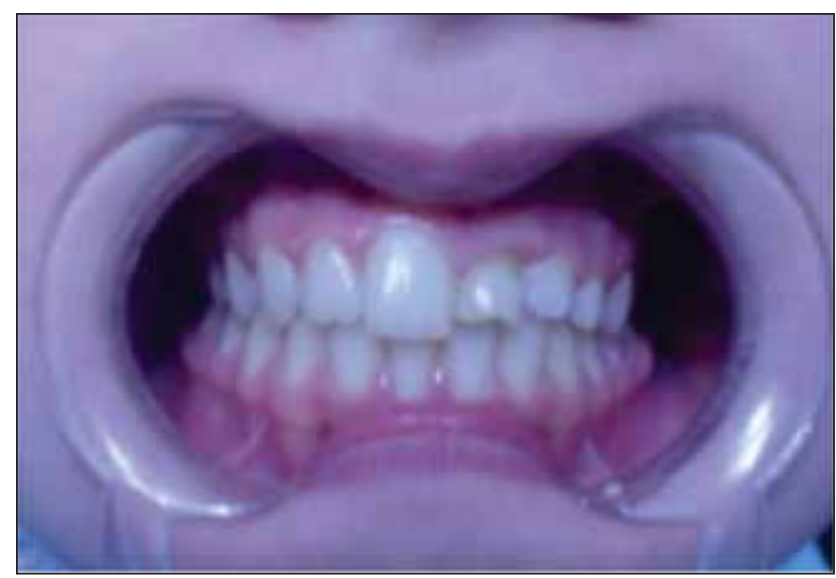

FIGURA 1. Vedere laterală şi frontală a ocluziei statice a pacientei G.F., la începutul tratamentului ortodontic 
nele suprapunându-se radiografic la nivelul jumătății coronare, spre incizal;

- 22 mezio-înclinat $45^{\circ}$ față de paralela la mediana maxilară şi aproape paralel ca poziţie cu 23 inclus, fără să se observe rizaliza patologică a lui 22 , de către coroana supraiacentă a lui 23 ;

- molarii secunzi definitivi cu apexul aproape închis;

- prezența celor patru molari de minte, coroanele fiind mineralizate.

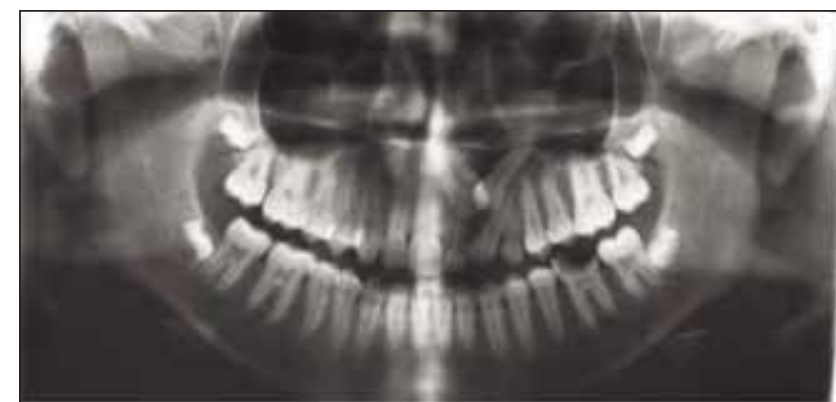

FIGURA 2. Ortopantomograma pacientei G.F. la începutul tratamentului ortodontic

În urma examenului clinic, a analizei modelelor de studiu şi a ortopantomogramei, planul de tratament propus şi acceptat de către pacientă şi părinți a fost:

- tratamentul leziunii carioase de la nivelul lui 36;

- igienizarea cavităţii bucale (detartraj şi periaj profesional);

- aplicare aparat ortodontic fix la arcada superioară;

- extracția lui 61 şi 63 (Fig. 3).

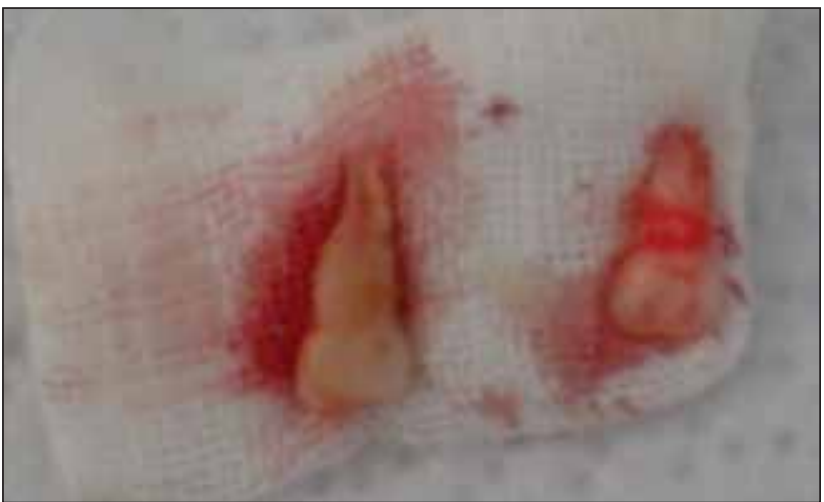

FIGURA 3. Dinții de lapte 61 şi 63 extraşi - se observă gradul redus de rizaliză fiziologică produs de 11 şi 13 incluşi

- abordare vestibulară chirurgicală cu descoperirea coroanelor lui 21 şi 23 şi aplicare de ataşe ortodontice cu ligatură metalică pentru tracțiunea ortodontică a dinților incluşi (Fig. 4)
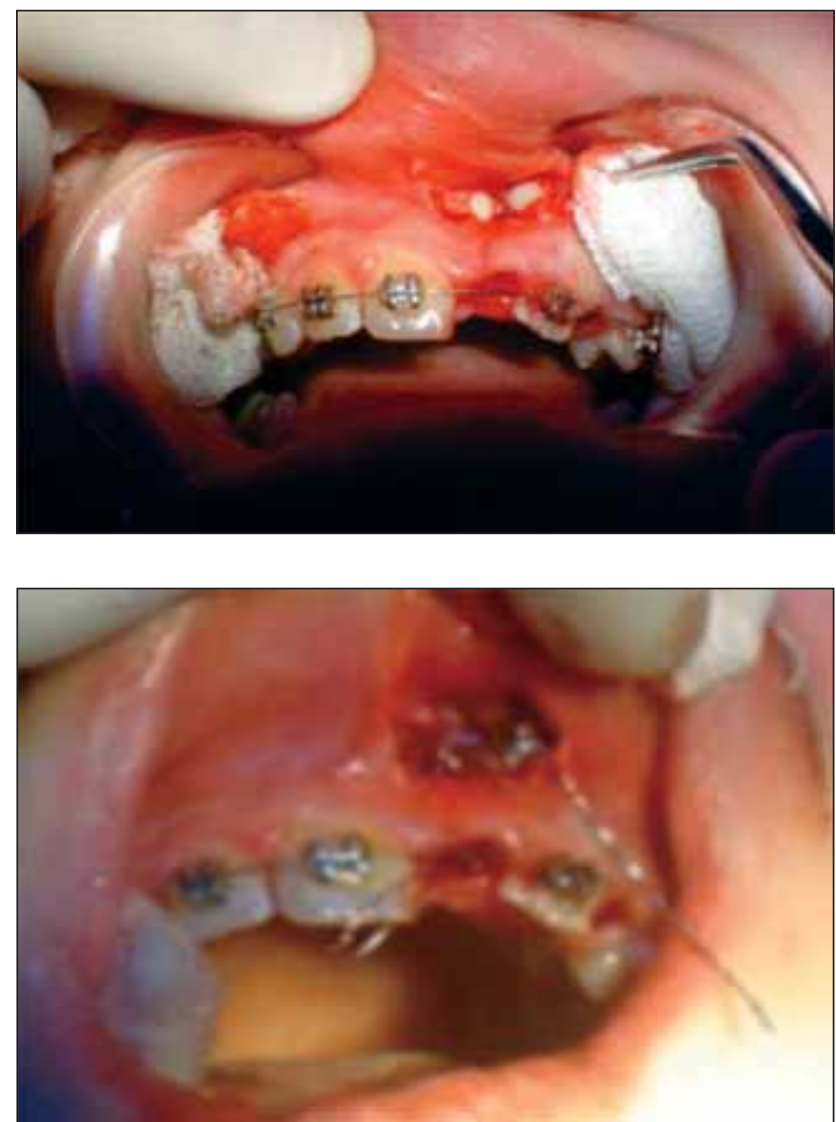

Figura. 4 Descoperirea chirurgicală a coroanelor lui 21 şi 23, cu aplicare de ataşe ortodontice

- având în vedere poziția coroanelor dinților incluşi, s-a efectuat tracțiunea elastică, cu vestibularizare şi distalizare a coroanei lui 23 şi ulterior vestibularizarea şi extruzia lui 11 (Fig. 5).

- pe parcursul tratamenului ortodontic au fost efectuate radiografii retroalveolare pentru contolul statusului parodontal şi radicular al dinţilor 21, 22 şi 23 (Fig. 6).

- după alinierea dinților incluşi maxilari, la 26 de luni s-a aplicat aparat ortodontic fix şi la arcada dentară mandibulară, pentru obținerea relațiilor neutrale la nivel molar şi canin, corespondența liniilor mediane şi interincisive, menținerea supraacoperirii frontale de $1 / 3$, cu intercuspidare maximă şi mişcări funcționale mandibulare în limite normale (Fig. 7 şi Fig. 8).

- după 40 de luni de terapie ortodontică fixă bimaxilară au fost îndepărtate aparatele fixe, s-a aplicat contenție linguală fixă canin-canin, pacientei fiindu-i recomandat control periodic la 6 luni (Fig. 9). 

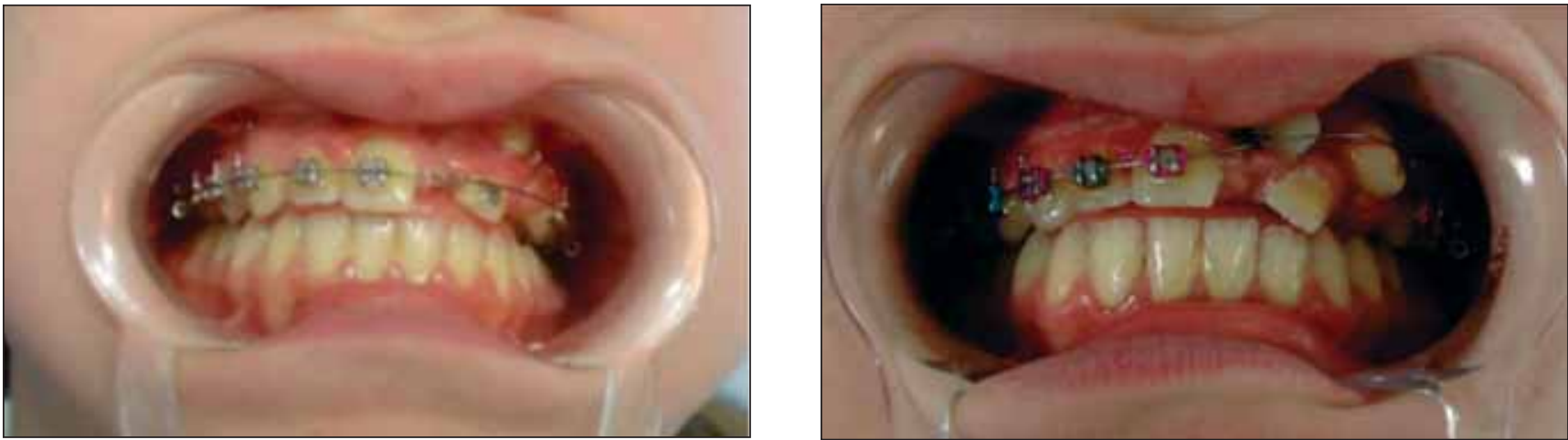

FIGURA 5. Etape din tratamentul ortodontic pentru tracțiunea ortodontică şi alinierea lui 21 şi 23 - de remarcat îndepărtarea bracketului de pe 22 şi neangajarea lui 22 în arcul ortodontic, astfel încât, prin mişcările ortodontice ale dinților vecini incluşi, rădăcina acestuia să fie cât mai puțin expusă riscului de rizaliză patologică
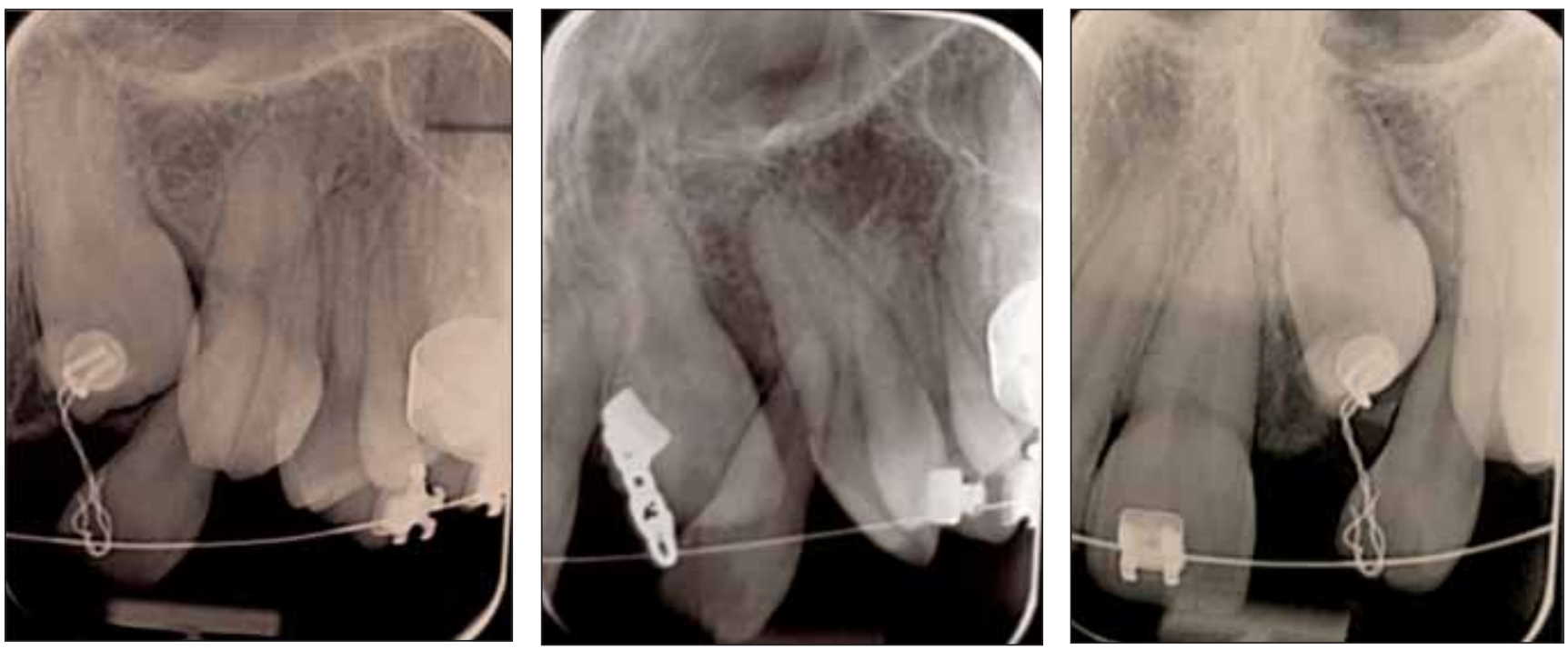

FIGURA 6. Radiografii periapicale de control efectuate pe parcursul tracțiunii ortodontice a dinților incluşi 21 şi 23.

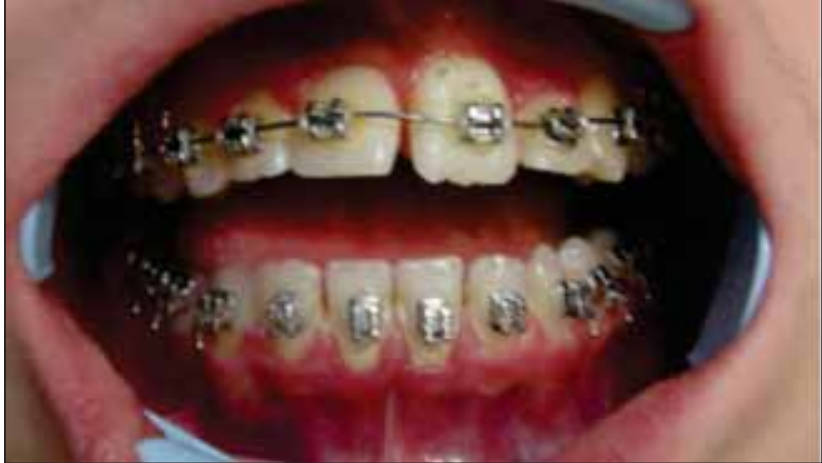

FIGURA 7. Imaginea arcadelor dentare după alinierea arcadei dentare maxilare

\section{CONCLUZII}

Tratamentul incluziei dentare reprezintă o provocare pentru practicieni, deoarece necesită stabilirea unui diagnostic precis, a unui plan de tratament complex care necesită o bună colaborare între medicii specialişti în ortodonție, chirurgie dento-alve-

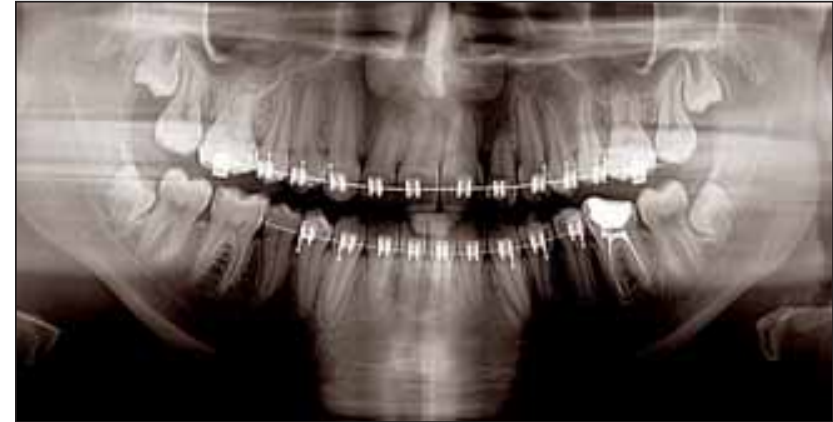

FIGURA 8. Radiografia panoramică înaintea îndepărtării aparatului ortodontic fix

olară şi parodontologie. Abordarea terapeutică a dinților incluşi în zona anterioară necesită adeseori o atenție deosebită, astfel încât rezultatul să satisfacă cerințele esteticii dentare ale pacientului, dar să asigure şi o bună funcționalitate a aparatului dentomaxilar (9). 

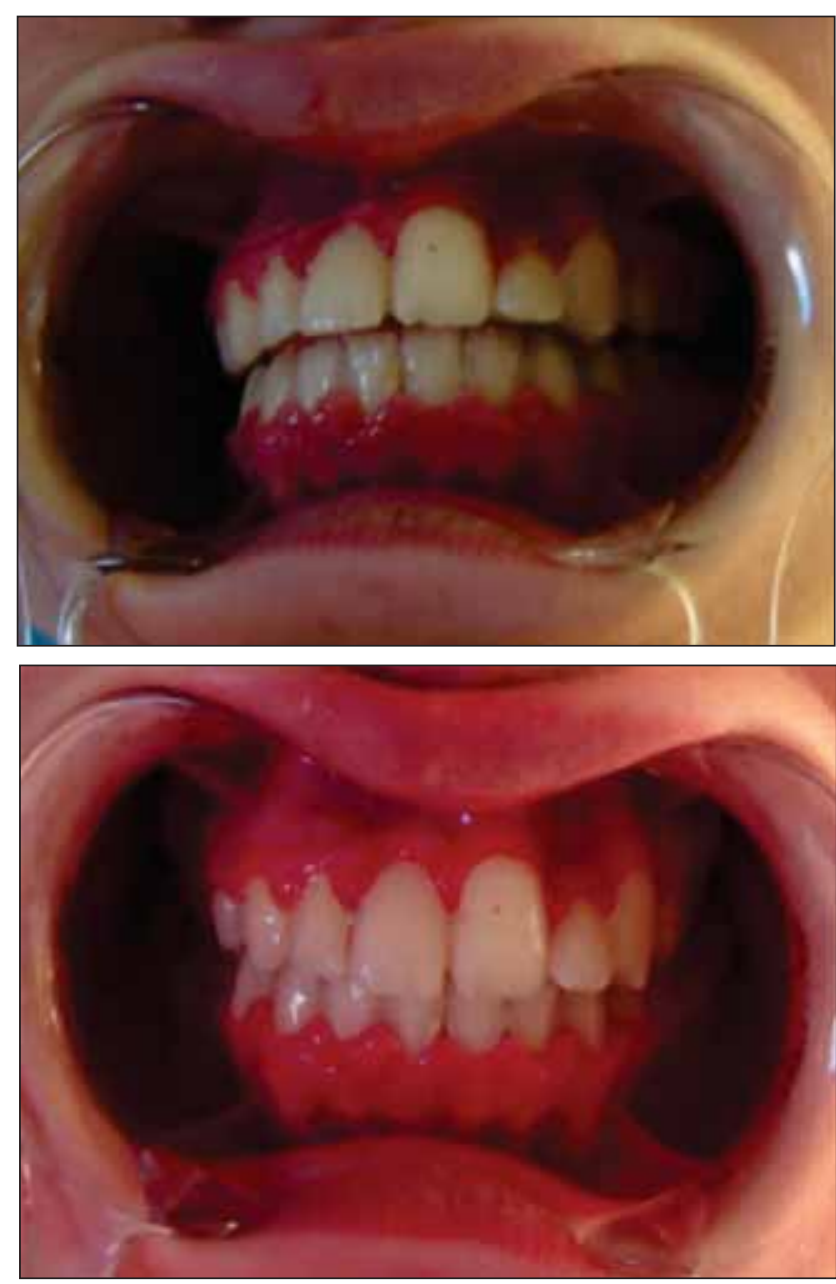

\section{BIBLIOGRAFIE}

1. Dorobăţ V., Stanciu D. Ortodonţie şi ortopedie dento-facială, Ed. Medicală, Bucureşti, 2003.

2. Ionescu E. Anomaliile dentare. Ed. Cartea Universitară, Bucureşti, 2006.

3. Roberts-Harry D, Sandy J. Orthodontics. Part 10: impacted teeth. Br Dent J 2004;196(6):319-327.

4. Zetu I., Păcurar M. Ortodonţie, vol. II -Tehnica arcului drept, Ed. Lyra, Tg-Mureş, 2000.

5. Decusară Mioara, Milicescu Viorica. Valoarea investigaţiei ortopantomografice în diagnosticul şi tratamentul anomaliilor dento-maxilare. Revista Română de Stomatologie, 2011, 57(4):253-258 . ISSN : 1843-0805 2069-6078.

6. Dachi S.F., Howell F.V. A survey of 3874 routine full-month radiographs II. A study of impacted teeth, Oral Surg Oral Med Oral Path 1961;14:1165-1169.

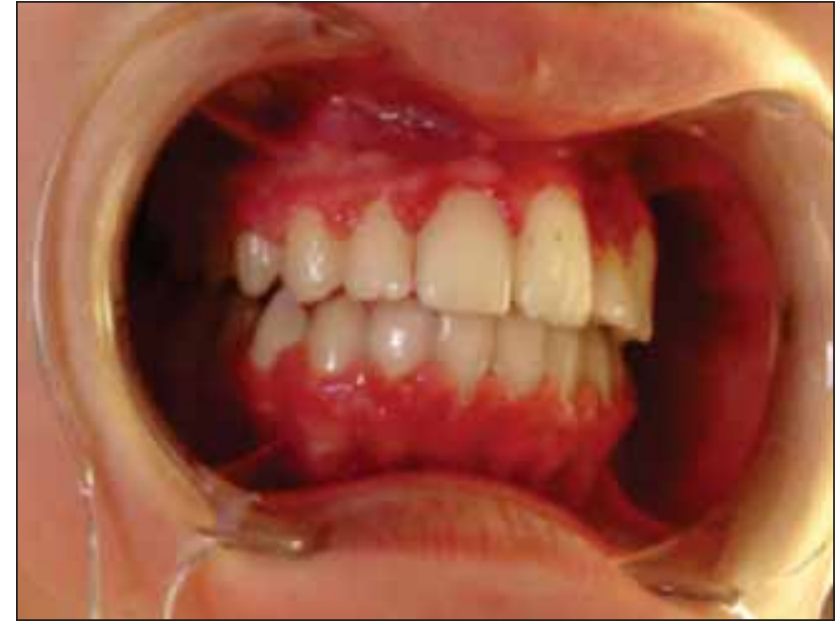

FIGURA 9. Vedere laterală şi frontală a arcadelor dentare la finalul tratamentului ortodontic

7. Ericson S., Kurol J. Longitudinal study and analysis of clinical supervision of maxillary canine eruption. Community Dent Oral Epidemiol 1986; 14:172-176.

8. Lacoste J.L. Désinclusion et mis en place des dents retenues. Encycl Med Chir (Elsevier Paris), StomatologieOdontologie II 1988; 23-492-A-10.

9. Şincar Dorina-Cerasella, Chiscop lulia, Rusu Magdalena, Decusară Mioara, Nicolau Al.-M., Leaţă R. Ethiopatogenic and imagistic considerations în the impaction of the wisdom teeth. Revista Română de Anatomie funcţională şi clinică, macro- şi microscopică şi de Antropologie, 2016, XV(2):18, ISSN: 1583-4026.

Conflict of interest: none declared Financial support: none declared 